Acknowledgements: We would like to thank the staff at the Royal Hospital for Children, Glasgow for their cooperation during this audit.

Disclosure of Interest: None declared

DOI: 10.1136/annrheumdis-2018-eular.7266

\section{AB1093 CAN DMARDS THERAPY MODIFY CLINICAL HISTORY OF OLIGOARTICULAR JUVENILE IDIOPATHIC ARTHRITIS (JIA)?}

E. Bertoldo ${ }^{1}$, C. Mansoldo ${ }^{2}$, F. Martinis $^{1}$, G. Dallagiacoma ${ }^{1}$, D. Biasi ${ }^{1}$, M. Rossini $^{1}$, S. Pieropan ${ }^{1}{ }^{1}$ Rheumatology Unit, ${ }^{2}$ Ophthalmology Unit, AOUI Verona, Verona, Italy

Background: Therapy of oligoarticular JIA is based on intrarticular injections of steroids, methotrexate and biotechnological therapy. ANAs-positive oligoarticular JIA patients with an early onset of disease have a consistent risk to develop uveites.

Objectives: The primary aim of this study is to evaluate longitudinally the effect of non-systemic therapy and of systemic immmunomodulating drugs (e.g MTX) on ANAs in JIA patients; secondary occurance of iridocyclitis was evaluated.

Methods: Monocentric retrospective not randomised study of 40 patients affected by oligoarticular JIA (ILAR classification) with ANA positivity at the baseline (TO, time of diagnosis). Patient of Group 1 received only intra-articular infiltrations or NSAID. Patients of Group 2 were treated with DMARDs (most of them with subcutaneous MTX $15 \mathrm{mg} / \mathrm{m} 2 /$ week) or MTX +biotechnlogical therapies. The assay for ANAs (I.I.F.) was assessed in all patients at T0, at T1 (12 months) and T2 (24 months). At 24 months was also recorded the occurence of uveitis during the follow up. Exclusion criteria were the ANAs negativity at T0 and other subgroups of JIA.

Results: Twenty-one patients $(52,5 \%)$ were treated with non-systemic therapy (Group 1), and ninenteen (47,5\%) with systemic immunomodulating therapy (Group 2). In Group 2 fifteen subjects were treated with MTX, one with MTX plus cyclosporine, one with only cyclosporine, two with MTX plus biotechnological agent (etarnecept and adalimumab). At T1, in Group 1 only one patient out of 20 $(4,8 \%)$ became ANAs negative versus $42,1 \%(8 / 19)$ of patients in Group 2 (p 0.0033 ). At T2 the incidence of ANAs positivity did not change in Group 1 (only $1 /$ 21 ANAs negative), while $42,1 \%$ of patients treated with systemic therapies were ANA negative ( $p$ 0.006). Three patients were lost at the follow up. The two patients who received bDMARDs in addition to MTX remained ANAs-positive both in T1 and T2. At the end of follow-up period eight uveitis have occured, six in ANAs positive patients of Group $1(6 / 21,28,5 \%)$ and two in ANA negatives patients in Group $2(2 / 19,10,5 \%)$

Conclusions: ANAs-positive patients treated with methotrexate seems to have higher possibility to became ANAs-negative versus patients treated with non-systemic immunomodulating therapy. It's known that MTX might prevent onset of uveitis in JIA, as shown in our results. Demostrating a negativization of antinuclear antibodies using MTX therapy could help to add a role of this drug in the disease history of the oligoarthritis.

Disclosure of Interest: None declared

DOI: 10.1136/annrheumdis-2018-eular.2612

\section{AB1094 ACUTE RHEUMATIC FEVER: NEW ASPECTS OF AN OLD DISEASE}

F. Martinis $^{1}$, S. Pieropan ${ }^{1}$, G. Dallagiacoma ${ }^{1}$, E. Bertoldo ${ }^{1}$, S. Picassi ${ }^{2}$, D. Biasi ${ }^{1}$, M. Rossini ${ }^{1}$, M.A. Prioli ${ }^{3}$. ${ }^{1}$ Rheumatology; ${ }^{2}$ Paediatrics; ${ }^{3}$ Cardiology, AOUI VERONA, Verona, Italy

Background: Acute rheumatic fever is a nonsuppurative sequela that occurs two to four weeks following group A beta-hemolytic Streptococcus (GABHS) pharyngitis. Despite its decline in incidence in Europe, rheumatic fever still represents a serious healthcare concern. The most common manifestations are arthritis and carditis, followed by chorea, erythema marginatum, and subcutaneous nodules. The diagnosis of ARF is clinical and requires satisfaction of revised Jones criteria as well as evidence of a recent streptococcal infection.

Objectives: Aim of this study was to highlight new emerging features of disease clinical presentation.

Methods: Data regarding patients who fulfilled the Revised Jones Criteria for acute rheumatic fever were retrospectively collected from January 1996 and July 2017. The following clinical and demographic data were obtained: patient sex, birth date, age at presentation, clinical manifestations, evolution of cardiac involvement after therapy.

Results: 35 patients (19 males, 16 females) were included. The mean age at diagnosis $7,9 \pm 4$ years (range $2-17$ ). Carditis was the most frequent manifestation, occurring in 31 patients $(89 \%)$. Other common symptoms were fever $(91 \%)$, artrhtiris $(43 \%)$ or arthralgias $(54 \%)$ and chorea $(20 \%)$. In 6 out of 7 patients chorea occurred together with carditis. Cardiac auscultation revealed new pathologic murmurs only in $49 \%$ of cases. Echocardiography detected cardiac involvement in the absence of auscultatory findings (subclinical carditis) in 11 patients at the time of diagnosis. In 3 cases ultrasound examination became positive within 4 weeks. Throat cultures were negative in $37 \%$ of cases. Anti-streptolysin O (ASO) and anti-desoxyribonuclease B (ADB) antibodies titers did not bear correlation with the severity of cardiac involvement.

Conclusions: In our casistic, carditis was the most common and worrysome manifestation of ARF. Detection of cardiac involvement is still challenging and echocardiography testing should be performed even in the absence of abnorma auscultation findings. If the initial ultrasound is negative but clinical suspiciun remains high, US investigation should be repeated, given that rheumatic carditis can evolve over weeks to months. Early detection and treatment of manifestations improves outcome as in all the cases of this series.

Streptococcal serology is most helpful in the diagnosis of ARF because culture or detection of the organism is usually no longer possible by the time ARF presents. The severity of clinical manifestations, particularly of carditis, does not correlate strictly with ASO and ADB titer.

Sydenham chorea, which usually has a longer latent period (up to 6 months), tends to occur earlier in the disease course, presenting in the acute phase in this series.

\section{REFERENCES:}

[1] Gewitz MH, et al. Revision of the Jones Criteria for the Diagnosis of Acute Rheumatic Fever in the Era of Doppler Echocardiography A Scientific Statement From the American Heart Association. Circulation. 2015 May 19;131(20):1806-18

[2] Parks T, et al. ASO titer or not? When to use streptococcal serology: a guide for clinicians. Eur J Clin Microbiol Infect Dis. 2015 May;34(5):845-9.

Disclosure of Interest: None declared DOI: 10.1136/annrheumdis-2018-eular.4725

\section{AB1095 LONG-TERM IMPACT OF JUVENILE IDIOPATHIC ARTHRITIS ON QUALITY OF LIFE OF ADULT PATIENTS IN GREECE}

G.C. Paskalis ${ }^{1}$, D. Dimopoulou ${ }^{2}$, M. Trachana ${ }^{3}$, C.C. Theocharidou ${ }^{1}$, P. PratsidouGertsi $^{3}$, T. Oikonomou ${ }^{2}$, T. Dimitroulas ${ }^{2}$, A. Garyfallos ${ }^{2} .{ }^{1}$ Aristotle University, Thessaloniki, Greece; ${ }^{2} 4$ th Department of Internal Medicine; ${ }^{3} 1$ st Department of Pediatrics, Pediatric Immunology and Rheumatology Referral Centre, Aristotle University, Thessaloniki, Greece

Background: Juvenile Idiopathic Arthritis (JIA) is the most common rheumatic disease in childhood and affects negatively both physical and psychosocial functioning

Objectives: To explore the long-term impact of JIA on quality of life of adult patients in Northern Greece.

Methods: Adult patients with a definite diagnosis of JIA were assessed by the SF-12v2 questionnaire in the outpatient transition (from Paediatric to adult Rheu matology) clinic of Hippokratio Hospital of Thessaloniki. SF-12 questionnaire is a quality of life assessment tool and consists of a Physical Component Summary (PCS) and a Mental Component Summary (MCS). PCS and MCS of the patient group were compared to an age-matched control group, using t-test or MannWhitney $U$ test, as appropriate. Moreover, percentages of patients and controls who were severely affected ( $<45$ points in PCS or MCS) were compared, using Chi-squared test. Finally, correlation between the two summary components of SF-12 of patients was measured, using Spearman's rho. Statistical analysis was done using SPSS software. Level of statistical significance is $\mathrm{p}<0.05$.

Results: A total of 50 patients and 135 controls were enrolled in the study. The median (IQR) patient age was $32^{10}$ years and disease duration was $24^{9,5}$ years. PCS scores of patients group were statistically significantly lower compared to control group $(\mathrm{p}=0.021)$ and more patients than controls scored low values $(<45$ in PCS $(22 \%$ versus $6.7 \%$, odds ratio, $4.0[95 \% \mathrm{Cl}, 1.5,10.2] ; \mathrm{p}=0.007)$. MCS scores of patients were slightly better than scores of controls (mean difference $3.67[95 \% \mathrm{Cl}, 0.44,6.90] ; \mathrm{p}=0.026$ ), but the severely affected were similar in both groups (odds ratio, $0.6[95 \% \mathrm{Cl}, 0.3,1.2] ; p=0.174$ ). No correlation between PCS and MCS was found $(\mathrm{p}=0.48$ ).

Conclusions: There is an apparent impact of JIA on many patients' quality of life specifically in terms of their physical health, that persists for many years after disease onset, which is in line with studies from other countries. This could be related to disease severity, disease subtype and duration, socioeconomic status and availability of treatment options. Interestingly, JIA wasn't found to affect the patients' mental health. A more specific psychometric test would be appropriate for in-depth analysis and confirmation of this result. Study design did not allow subgroup analysis according to JIA subtype, disease severity or duration, highlighting the need for long-term outcome studies focusing on the risk factors which may be involved. 
REFERENCES:

[1] Foster $\mathrm{H}$, et al. Outcome in adults with juvenile idiopathic arthritis: A quality of life study. Arthritis \& Rheumatism. 2003;48(3):767-775

[2] Kontodimopoulos N, et al. Validity of SF-12 summary scores in a Greek general population. Health Qual Life Outcomes. 2007 Sep 28;5:55

[3] Minden $\mathrm{K}$, et al. Long-term outcome in patients with juvenile idiopathic arthritis. Arthritis \& Rheumatism. 2002;46(9):2392-2401

[4] Anink J, et al. Long-term quality of life and functional outcome of patients with juvenile idiopathic arthritis in the biologic era: a longitudinal follow-up study in the Dutch Arthritis and Biologicals in Children Register. Rheumatology. 2015;54(11):1964-1969

Disclosure of Interest: None declared

DOI: 10.1136/annrheumdis-2018-eular.6604

\section{AB1096 OBSERVATIONAL SAFETY STUDY OF GOLIMUMAB IN TREATMENT OF POLYARTICULAR JUVENILE IDIOPATHIC ARTHRITIS USING THE GERMAN BIOLOGICS JIA REGISTRY}

G. Horneff ${ }^{1,2}$, A. Klein ${ }^{1}$, on behalf of BIKER registry working group. ${ }^{1}$ ASKLEPIOS, Sankt Augustin; ${ }^{2}$ University of Cologne, Cologne, Germany

Background: Golimumab (GLM) received European marketing authorisation for treatment of polyarticular JIA (pJIA). The long-term safety of GLM in clinical preactice has not been characterised.

Objectives: The aim of the present project is to conduct a post-authorisation safety study to monitor long-term safety of subcutaneous GLM in the treatment of pJIA in routine clinical practice setting.

Abstract AB1096 - Table 1

\begin{tabular}{|c|c|c|c|c|c|}
\hline Cohort & $\left({ }^{1} \mathrm{GOL}\right.$ & $\begin{array}{c}\left(^{2} \text { concurrent }\right. \\
\text { TNFi (ETA/ADA) }\end{array}$ & $\begin{array}{c}\left(^{3} \text { concurrent }\right. \\
\text { MTX }\end{array}$ & $\begin{array}{l}\left({ }^{4} \text { historic }\right. \\
\text { TNF }\end{array}$ & $\begin{array}{c}\left({ }^{5} \text { historic }\right. \\
\text { MTX }\end{array}$ \\
\hline $\mathrm{n}$ & 18 & 53 & 13 & 2103 & 1517 \\
\hline Age, median [IQR] & $\begin{array}{c}13.9 \\
{[12.8 ; 15.2]}\end{array}$ & $11.6[7.9 ; 14.8]$ & $\begin{array}{c}10.5 \\
{[4.6 ; 12.6]}\end{array}$ & $\begin{array}{c}12.7 \\
{[8.9 ; 15.5]}\end{array}$ & $\begin{array}{c}10.2 \\
{[5.6 ; 13.9]}\end{array}$ \\
\hline $\begin{array}{l}\text { Disease duration, } \\
\text { median [IQR] } \\
\text { Pretreatment }\end{array}$ & $\begin{array}{c}8.0 \\
{[2.5 ; 11.4]}\end{array}$ & $2.6[0.9 ; 6.5]$ & $0.2[1.1 ; 0.6]$ & $\begin{array}{c}3.0 \\
{[1.1 ; 5.8]}\end{array}$ & $\begin{array}{c}0.9 \\
{[0.4 ; 2.8]}\end{array}$ \\
\hline NSAID, n(\%) & $16(89)$ & $44(83)$ & $11(85)$ & $1886(90)$ & $\begin{array}{l}1293 \\
(85.2)\end{array}$ \\
\hline $\begin{array}{l}\text { Steroids systemic, } \\
\mathrm{n}(\%)\end{array}$ & $10(56)$ & $27(51)$ & $5(38)$ & $1030(49)$ & $\begin{array}{c}315 \\
(20.7)\end{array}$ \\
\hline MTX, n(\%) & $18(100)$ & 49(92) & & $1794(85)$ & \\
\hline $\begin{array}{l}\text { other DMARDs, n } \\
(\%)\end{array}$ & 7 (39) & $4(8)$ & 0 & $636(30)$ & $143(9.4)$ \\
\hline $\begin{array}{l}\text { Biologics } \\
\text { Concomitant }\end{array}$ & $14(78)$ & $17(36)$ & 0 & $226(11)$ & 0 \\
\hline Treatment & & & & & \\
\hline NSAID, n(\%) & $8(44)$ & $38(72 \%)$ & 12(92) & $1544(73)$ & $\begin{array}{l}1394 \\
(91.9)\end{array}$ \\
\hline $\begin{array}{l}\text { Steroids systemic } \\
\mathrm{n}(\%)\end{array}$ & 0 & $11(21 \%)$ & $4(31)$ & $619(29)$ & $\begin{array}{c}359 \\
(23.7)\end{array}$ \\
\hline MTX, n(\%) & $13(72)$ & $39(74)$ & $13(100)$ & $1389(66)$ & $\begin{array}{l}1517 \\
(100)\end{array}$ \\
\hline $\begin{array}{l}\text { other DMARD,s n } \\
(\%)\end{array}$ & 0 & 0 & 0 & $233(11)$ & $57(4)$ \\
\hline $\begin{array}{l}\text { Baseline Disease } \\
\text { Activity }\end{array}$ & & & & & \\
\hline $\begin{array}{l}\text { Active joints, } \\
\text { median [IQR] }\end{array}$ & $5[2 ; 6]$ & $4[2 ; 9]$ & $9[7 ; 13]$ & $3[1 ; 7]$ & $3[2 ; 7]$ \\
\hline $\begin{array}{l}\text { Phys Global, } \\
\text { median [IQR] }\end{array}$ & $37[19 ; 56]$ & $33[24 ; 49]$ & $59[43 ; 75]$ & $\begin{array}{c}48 \\
{[26 ; 71]}\end{array}$ & $\begin{array}{c}43 \\
{[24 ; 67]}\end{array}$ \\
\hline $\begin{array}{l}\text { JADAS_10, } \\
\text { median [IQR] }\end{array}$ & $12[6 ; 16]$ & $12[8 ; 16]$ & $21[18 ; 24]$ & $13[8 ; 18]$ & $13[8 ; 18]$ \\
\hline
\end{tabular}

Methods: Monitoring of GLM in 200 pts with polyarticular JIA (cohort 1) in clinical practice will be performed by the German BiKeR Registry compared to a concurrent cohort 2 with 400 pts newly treated with alternative (approved) TNF-inhibitor, a concurrent cohort 3 with 500 pts newly starting methotrexate, a historic cohort 4 of patients treated with TNF-inhibitors and a historic cohort 5 never exposed to biologics but treated with methotrexate. Efficacy will be assessed by single disease activity markers and JADAS10, safety will be assessed by adverse event reporting and monitoring with a special interest on serious infections including opportunistic infections and TB, malignancies, autoimmune processes and exposure during pregnancy.

Results: Recruiting of three new cohorts 1-3 started in July 2017. Historic control cohorts 4 and 5 were obtained from the BIKER data base. Cohort 4 was recruited from 2006 to 2016, cohort 5 from 2005 to 2011. Baseline patients' characteristics are outlined in table 1. So far, patients of the GLM cohort 1 were older, had a much longer disease duration and received pre-treatment with other biologics more often. All patients in this cohort received combination with methotrexate. Since so far GLM is approved for children with body weight of at least $40 \mathrm{~kg}$ and in combination with methotrexate, differences were expected. Baseline disease activity indicators are within the range of alternative TNF inhibitors and the historic cohor 4 while patients of the concurrent methotrexate cohort receiving their first treatment approach had the highest baseline disease activity.

Conclusions: The BiKeR registry has been collecting data from JIA patients treated with approved biologics in routine clinical practice since 2001. To provide context for interpreting long-term safety and effectiveness of data for GLM, analysis will also include data from contemporary pJIA patients treated with alternative TNF inhibitors and methotrexate.

Acknowledgements: This project of the BIKER registry is supported by an unrestricted grant from MSD, Germany

Disclosure of Interest: None declared

DOI: 10.1136/annrheumdis-2018-eular.2165

\section{AB1097 PROGRESSIVE PSEUDORHEUMATOID DYSPLASIA (PPRD) IN SIBLINGS MIMICKING INFLAMMATORY ARTHROPATHY}

S. Khan ${ }^{1}$, Z. Afridi ${ }^{2}$, I. Malik ${ }^{1} .{ }^{1}$ Rheumatology; ${ }^{2}$ Pediatrics, Lady Reading Hospital, Medical Teaching Institution, Peshawar, Pakistan

Background: Progressive pseudorheumatoid dysplasia is a rare condition with an incidence of 1 in 1 million.

Objectives: Keeping in mind rare disorders when dealing with children in rheu matology clinics.

Methods: A 12 years old girl was referred to rheumatology by general practitioner. Her main complaint was difficulty walking, standing up from sitting position, short stature and nodulosis of interphalangeal joints. Initially she had muscle weakness which was thought to be contributing to her gait problem and difficulty standing.

Investigation revealed myopathic changes on electromyography though her CK was entirely normal. Other investigations including routine bloods and inflammatory markers were normal. Immunology was negative. X-rays revealed reduced joint spaces in interphalangeal joints and epiphyseal dysplasia in elbows and hips. On examination there was no evidence of any synovitis. The child was of short stature i.e less than the 3rd percentile on growth chart. She had a waddling gait. There was nothing in the history to suggest previous or current inflammatory arthropathy.

Interestingly this child had another younger sibling, 7 years old girl who had similar changes in her hands.

Results: Based on history, investigations, examination and familial characteristic we felt that these two kids (siblings) had PPRD. It usually happens at the age of 3 to 8 years. Walking pattern, fatigue, weakness and intermittent episodes of stiffness are the common symptoms. Other feature is reduced joint spaces in knees and hips. At birth kids are usually of normal height but by adulthood they are short statured. They also can have calcium deposition around the joints. PPRD is caused by mutation in WISP3 gene which is responsible for bone growth and cartilage maintenance and is inherited in an autosomal recessive pattern.

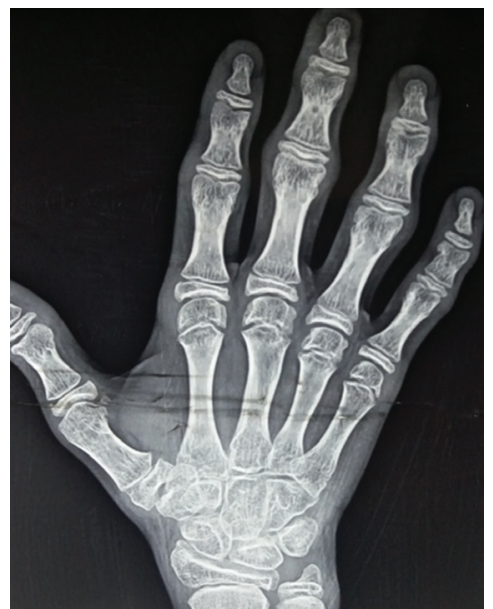

Abstract AB1097 - Figure 